\title{
English-Medium Instruction in Self-Financing Tertiary Institutions in Hong Kong - Views and Practices from the Students
}

\author{
Marine Yeung ${ }^{1} \& \mathrm{Vic} \mathrm{Lu}^{1}$ \\ ${ }^{1}$ School of Arts and Humanities, Tung Wah College, Hong Kong \\ Correspondence: Marine Yeung, School of Arts and Humanities, Tung Wah College, 90A, Shantung Street, \\ Mongkok, Kowloon, Hong Kong. Tel: 852-3468-6694. E-mail: marineyeung@twc.edu.hk
}

\author{
Received: June 9, 2018 Accepted: July 10, $2018 \quad$ Online Published: July 11, 2018 \\ doi: 10.5539/elt.v11n8p28 URL: http://doi.org/10.5539/elt.v11n8p28
}

\begin{abstract}
The medium of instruction (MOI) has been a bone of contention in Hong Kong, a former British colony, since its colonial days. Despite the Hong Kong government's effort to promote the "biliterate and trilingual" language policy, advocating Cantonese, English and Putonghua as the three official spoken languages and emphasizing the importance of literacy in both written Chinese and English, most tertiary institutions today still adopt English as the medium of instruction (EMI). However, with the expansion of tertiary education in the early 1990s and the decline in the general English language proficiency of university students, some university lecturers have found it difficult to teach in English as required. This raises the issue of the practicality of the indiscriminate adoption of the EMI policy at tertiary level, particularly at the self-financing tertiary institutions where students are generally known to have under-performed in the English subject. In order to understand whether or how the EMI policy is upheld in these institutions, focus group interviews were conducted with students from various programmes of five self-financing tertiary institutions in Hong Kong. The findings indicate these students' strong preference for English-medium instruction with the belief that it can improve their English proficiency, though their actual approaches to coping with the demand on their limited English and how they view and use the three languages in class deserve policy makers' serious consideration.
\end{abstract}

Keyword: EMI, English-medium education, English proficiency, higher education, language policy, medium of instruction, self-financing tertiary institutions, Hong Kong

\section{Background}

\subsection{Sociolinguistic Environment and Medium of Instruction in Hong Kong}

The medium of instruction (MOI) has been a bone of contention in Hong Kong since its colonial days. While it is evident from research that using the mother tongue as the medium of learning is more effective than using English (e.g. Brimer et al., 1985; Lo \& Lo, 2014), the formulation of the MOI policy has always been motivated by political agenda and has to be understood in the broader social and political context (Tsui, 2004). English was undoubtedly the MOI of most secondary schools and all universities in Hong Kong before the handover in 1997, but with the change of the sociolinguistic environment in Hong Kong over the past two decades, its predominant role as the main if not sole medium of instruction is not accepted without question.

Since the 1970s, both English and Chinese have been the official languages of Hong Kong; Putonghua, the national language of the People's Republic of China, has been added to the mix following the "biliterate and trilingual" language policy introduced by the Hong Kong SAR government. This policy to a certain extent matches the linguistic profile of the society, with the percentage of its trilingual population growing over the past few decades from 17\% in 1983 to 63\% in 2003 (Bacon-Shone \& Bolton, 2008). However, in business and professional contexts, English remains prominent in both the public and private sectors as the professional medium of written communication; Cantonese, the mother tongue of the majority population of Hong Kong, remains the major medium of spoken communication, and Putonghua still plays a rather limited role in business and professional communication (Evans, 2010).

Given such a social context, the continued dominance of English in education is understandable; yet the growing influence of Putonghua and the prominence of Cantonese in the reality of the Hong Kong society has not been officially reflected by the MOI policy. The mother tongue teaching policy implemented at primary school and 
junior secondary school may reflect an attempt to match such a change, but the policy has antagonized various stakeholder groups ( $\mathrm{Li}, 2009)$. At the tertiary level, the pressure to conform to the EMI policy is even higher as English is still considered a valuable asset that enhances graduates' desirability in the job market, and internationalization often means using English as the medium of instruction in higher education (Phillipson, 2006). The demand for English medium education remains so strong that of the eight government-funded universities in Hong Kong, six continue to officially adopt English as the MOI, and the other two adopt a bilingual or trilingual policy with English still playing a prominent role. Even the Chinese University of Hong Kong, which laid down Chinese as the principal language upon its establishment in 1964 and has an official bilingual policy, has also succumbed to the pressure from the societal needs for both Chinese (written Chinese and vernacular Cantonese) and English and has been offering more courses in English since 2004 (Li, 2013). Simply put, English is still the language of choice of the key stakeholders of education, including employers, parents and schools themselves. The "bi-literate and trilingual" language does not seem to have brought about any obvious impact on the long-standing EMI policy among universities and tertiary institutions in Hong Kong.

\subsection{Disparity Between Espoused EMI Policy and Actual Implementation}

However, another group of stakeholders, the teachers, would beg to differ. With the expansion in university education from being accessible to just around $2 \%$ of the student population in the 1980 s to about $18 \%$ in the mid-1990s (Howlett, 1997), some university lecturers, particularly those in science faculties, have found it difficult to teach in English as required (e.g. Flowerdew, Li \& Miller, 1998; Walters \& Ralia, 1998). The shift of tertiary education of Hong Kong from elitist to mass education inevitably results in a decline in the general English language proficiency of university students. The decline in English standards may also have been aggravated by the change of MOI to Chinese in primary and secondary schools, which has been shown to have adverse effects on language learning (e.g. Poon, 2004; Lin \& Morrison, 2010). As a result of all of these, the "declining standard of English" is already a discursive reality, and learning in English has become more of a challenge to the average tertiary student.

This challenge is not unnoticed by some of the leading universities in the territory, such as the University of Hong Kong and the Chinese University of Hong Kong. The University of Hong Kong established a Language Policy Committee in 2005 to review the implementation of the EMI policy on the campus and coordinate language enhancement activities; similarly, The Chinese University of Hong Kong set up the Committee on Bilingualism in 2005 to uphold its bilingual tradition, and on the Committee's recommendation, the Committee on Language Enhancement was set up in 2006. These two leading universities in Hong Kong have made an effort to review the current practices, reassert their MOI policies, and provide language learning support to their students accordingly.

In other universities, however, little has been done in relation to the MOI on their campuses. For example, according to Li, Leung and Kember (2001), the EMI policy has long become nominal at the Hong Kong Polytechnic University as barely half of the instruction is in English. In higher education in Hong Kong, the mismatch between espoused theory or policy and language use is evident; though some higher education institutions have revised their language policies, few appear to admit to the disparities, and little has been done to remove the discrepancy ( $\mathrm{Li}$, Leung, \& Kember, 2001). In other words, the issue is largely ignored in the tertiary education sector in Hong Kong, with hardly any research being done into the implementation of such a policy.

It is against this background that the need to review the implementation of the EMI policy in the self-financing tertiary institutions is brought up. It is not hard to surmise that at these institutions, whose student intakes tend to fall into the lower notch, the difficulty in teaching and learning in English may be conceivably greater, leading to a bigger policy-practice gap. The issue of the practicality of the indiscriminate adoption of the EMI policy at tertiary level has become more a matter of concern; as the EMI policy may have been implemented in response to stakeholders' wishes at the expense of students' learning. In order to prompt action from policymakers, evidence needs to be gathered, and the voices of these teachers and students themselves, the primary yet rather neglected stakeholder groups, need to be heard.

\subsection{Alternative Language Policies}

Meanwhile, public opinion has been found to be in favour of bilingual education as shown by the results of the survey conducted by the Social Science Research Centre of the University of Hong Kong in 2003, in which a majority (79\%) of the 1,060 interviewees indicated preference for "Cantonese and English" rather than "mainly English" or "mainly Cantonese" alone as the teaching medium in secondary schools (Bacon-Shone \& Bolton, 2008). Some earlier researchers (e.g. Li, 1999) have also pointed out that judicious use of code-switching, a form of bilingualism, serves sound pedagogical purposes, and legitimating this approach might be a way out of the 
complex language situation in education in Hong Kong. From a more social-linguistic perspective, the adoption of bilingual or multilingual language policies could help preserve and promote local languages and cultures to facilitate genuine international exchange and counteract the monopoly of English in higher education (Kirkpatrick, 2011).

From a purely educational perspective, students' mother tongue (L1) is the most powerful medium for thinking (Vygotsky, Rieber, \& Carton, 1987) and clearly has a potential role to play in foreign language teaching and content-based learning (Lin, 2015). It stands to reason that in a learning situation where only English as a second language (L2) is used as a medium of instruction, learners are disadvantaged as they have to make sense of the instructional tasks, attain required linguistic competence and master the content itself at the same time (Chaudron, 1988). Such insight gained from previous research in bilingual education, and the signs of change in the sociolinguistic environment in the society and on the tertiary campuses, however, do not seem to have been considered in the formulation of language policy. The current language policy in Hong Kong resembles one that has evolved from a series of top-down directives irrespective of public opinion, which has bolstered the powerful and dominant at the expense of the indigenous (Helot \& Laoire, 2011, p. xv); however, with the emergence of new frameworks of language policy in recent years (e.g. Corson, 2009; Ricento, 2006), there has been a shift of focus from authoritative top-down processes to implementation at the micro-level, and a step towards this new approach may bring us closer to the resolution of the problem. This would necessitate a better understanding of the ecologies of language use in the increasingly multilingual environment in Hong Kong classrooms.

The study was exploratory in nature and aimed to tap into the experiences and opinions of educators and students from the self-financing tertiary institutions in Hong Kong about the implementation of the EMI policy, their language practices and their perceptions about the use of Chinese and English in teaching and learning. The findings reported here mainly focus on those derived from the students' perspective. On the basis of the findings, recommendations for policy change will be made. Findings from the study may encourage stakeholders to reflect on the changing sociolinguistic environment of Hong Kong and policymakers to review the current MOI policy in search of one that would optimize students' learning.

\section{Data Collection}

\subsection{Participants}

Teachers and students from a variety of undergraduate programmes in science, social science, business, and humanities disciplines from five of the self-financing tertiary institutions in Hong Kong were invited to participate in the study. At the time of the study, there were fewer than ten degree-offering self-financing tertiary institutions in the city. The five participating in the study were the more established ones with stable student intakes. The sample was therefore considered to be representative enough to reflect the more prevailing views among this group of stakeholders.

This paper mainly reports findings gathered from the twelve groups of students from these five institutions. Each group consisted of six to eight student participants, making a total of 79 . There were both males and females in each group, and the participants were all native Cantonese speakers aged between 19 and 21 in different years of their studies. Of these twelve groups, two groups were from science degree programmes, three from business degree programmes, four from social science degree programmes and three were from arts and humanities degree programmes. It is worth noting that one of the groups was from a programme related to Chinese studies. They were invited on the ground that their apparently natural inclination towards the Chinese language would enable them to view the issue of the medium of instruction from a distinctive perspective.

\subsection{Data Collection and Analysis}

Qualitative data was collected via focus group interviews with the twelve groups of students. Compared with other data collection methods, interviewing is highly suitable for obtaining information based on personal emotions, feelings, experiences and insights, or about sensitive issues (Wisker, 2001). As this study was meant to be an exploration of the stake-holders' beliefs, perceptions and subjective experiences, and the issue of MOI may be considered a sensitive one by some teachers and students, interviewing was the main instrument of data collection in this study. In particular, the focus group is a research instrument that can elicit detailed data about people's perceptions and impressions in their own words (Stewart \& Shamdasani, 1990, p. 140). It is particularly suitable for research involving young adults as they tend to influence or be influenced by each other in real life, and a focus group provides an environment that allows for such interaction (Casey \& Krueger, 2000). Students were therefore interviewed in groups rather than individually for the purpose of this study.

Each group interview consisted of students from the same discipline, as homogeneity of the group can ensure 
more free-flowing and sincere discussion among the participants (Dawson et al., 1993; Morgan \& Krueger, 1993). The focus group interview centred around participants' experiences in learning in Cantonese, English and Putonghua, their language preferences and their concerns about learning in any one of these languages. The data were expected to help address three major research questions from the students' perspective:

1) How far was the EMI policy observed in the English-medium self-financing tertiary institutions in Hong Kong?

2) How and how well did these students cope with English-medium instruction?

3) Given a choice, what language(s) would they prefer to be the medium of instruction?

The interviews were semi-structured, lasting 45 minutes to 1 hour 30 minutes. All the interviews were recorded and transcribed for content analysis. Main ideas were categorized and organized into themes and interpreted with consideration of participants' expressions and the context of their use. Data from across the groups were then compared, contrasted and synthesized where appropriate in relation to the research questions. Before the interviews, the participants were briefed on the purpose of the study and invited to give their consent. They were informed that the findings would only be used for academic purposes, and that they had the right to withdraw from the study at any time.

\section{Results and Findings}

\subsection{Students' Perception of the MOI Policy of their College}

Concerning the MOI policy of their colleges, most of the student participants interviewed were not very aware of the existence of such policies at their colleges, but they assumed that if such a policy existed, it should be EMI. They could infer that English was the MOI of their colleges from the following observations:

- Most of the documents and emails they received from their college were written in English;

- Some college functions or events, such as assemblies and orientation activities, were conducted in English;

- Most of the course materials were in English, and the teachers gave priority to English in their instructions;

- There were questions about the percentage of English use in the course evaluation forms;

- Other local universities and tertiary institutions followed the EMI policy, and so should theirs.

Although most students perceived English to be the main MOI, none of the students could report any formal channel in which they received information about the language policy of their colleges. In other words, from the students' perspective, such a policy was implicit rather than explicit. The language policy was however generally assumed to be EMI. One student described the EMI policy as an "unwritten protocol" at tertiary education, and he thought it was common knowledge that a college must adopt EMI if it was to be recognized by the Education Bureau, even though in reality there was no government regulation in this regard.

This confusion about the MOI of their institutions could be traced back to the language policy of their secondary schools. While most of the students reported without much hesitation whether it was a Chinese-medium (CMI) or an EMI secondary school that they came from, some appeared rather confused. In each group there were students who found it hard to identify the MOI of their previous schools; while most students could readily identify the MOI used at their school, further enquiries revealed that the majority of the schools did not consistently use the language that they claimed to be their MOI. There were students from CMI schools who had been allowed to choose whether to be instructed in Chinese or English in different subjects. Whether students claimed to have attended allegedly EMI or CMI secondary schools, most of them had been taught using materials in English but instructed in Cantonese or in mixed-code during the lessons.

The ambiguity of the MOI policy to the students could be attributed to the inconsistency of the government's language in education policy and the pressure from parents to use English as the medium of instruction. After a decade's effort in promoting mother-tongue teaching and learning, the Education Bureau of Hong Kong finally relaxed this policy (Education Bureau, 2010) and allowed CMI schools to offer more classes in English provided they met certain criteria. Many schools therefore have switched to the English medium for certain class levels or subjects (Kan, Lai, Kirkpatrick, \& Law, 2011). There still exists a gray area in senior-secondary years, particularly in CMI schools where students may opt to take public examinations in English (Evans \& Morrison, 2016).

Because of such changes in the MOI policy in Hong Kong schools, the majority of the participants had experienced instructions in both Chinese and English since primary school, whether or not of their own choice. This would allow them to form opinions on the issue based on real personal experience; this may, however, 
affect their perception or interpretation and therefore implementation of such policies. Even when a school or college claims itself to be an English-medium one, it is doubtful whether students would see the need to adhere to its language policy.

\subsection{Teachers' Language Use in the Tertiary Classroom}

Although the students were presumably from EMI institutions, there were scant reports of teachers using English only in class from the participants. Code-mixing was prevalent, and there appeared to be a common pattern of the use of English and Cantonese across these institutions.

When asked about the actual use of English in class, all the groups reported that English was the main medium of instruction in most lectures, with a few of the groups claiming that English was used up to $90 \%$ to $100 \%$ of the time. As for the teaching materials, assignments and assessments, the majority had no doubt that English was the only language used. It seemed that the EMI policy was more consistently adhered to in these areas.

The use of Cantonese was however more common in tutorials. In the most common cases, English was the dominant language used with Cantonese as the auxiliary one. In fewer cases, English and Cantonese, and occasionally Putonghua in the presence of mainland students, were equally used. In only a few cases the use of Cantonese was reported to outweigh that of English.

When asked under what circumstances their teachers would use Chinese, most students replied that Chinese was primarily used to explain more difficult concepts and terms related to the subject being taught and to give examples. Occasionally, teachers may also go off topic in Chinese so as to amuse students or attract students' attention. It was also pointed out that teachers used Chinese because students failed to understand in English. Another reason for teachers using Chinese was that teachers could teach at a faster pace so that they would not lag behind their teaching schedules. It seemed that the students understood why their teachers used Cantonese and had no objection to it.

The difference in the English-Chinese ratio in instruction seemed to vary depending on the subject and the discipline. Students' reports indicated that for core subjects, English usually accounted for 70 to 90 percent of class time; for general education courses, Chinese tended to take up 50 to 60 percent in general. Subjects in science disciplines involved a higher percentage of English use, and Chinese tended to be heard more frequently in arts and humanities subjects, especially those highly relevant to the Chinese or local contexts. While a few arts and humanities courses were reportedly being conducted mostly in Chinese, there were no reports of science subjects being delivered mainly in Chinese.

From the students' accounts above, it seems that the actual use of English by the teachers at their institutions did not affect their perception of English as the MOI. Further prompting revealed that these students considered the use of Cantonese or Putonghua to be reasonable and commonplace in some situations. In one particular course, since there were a few exchange students from mainland China who did not seem to understand English very well, the lecturer encouraged students to use "a language that everyone knows", implying that students should use Putonghua. In other words, since the "violation" of the policy is justifiable, when the students claimed the policy was EMI, they were apparently referring to the lectures and to certain courses and situations, while ignoring others when English was not used.

\subsection{Students' Use of Languages in and out of the Classroom}

In addition to low expectation of the teachers' adherence to the EMI policy in class, the students also did not make much effort to follow the policy themselves. While the teachers may have tried their best to stick to the use of English, the majority of these students did not. They admitted that during their discussion in class, they would not use English among themselves unless the teacher insisted they speak English; outside of the classroom, in their consultations with the tutors, they would not use English either unless the tutor requested them to. Of all the students interviewed, only one student reported that he would speak English voluntarily and would only switch to Chinese when he failed to express himself in English. Most other students, however, would abandon speaking English if it was not a requirement.

Therefore, the EMI policy, as far as the students were concerned, were confined to the teachers' use of English in the lectures and perhaps the materials used in the courses.

\subsection{The Overwhelming Support of the EMI Policy}

When asked how the three languages should be used at tertiary level, that is, what the MOI or more broadly the language policy should be, the majority of the students asserted without much hesitation that English should be adopted as the medium of instruction, even for the group of students from a programme in the study of Chinese. 
Their arguments were mainly related to the acquisition of the English language and the importance of the language to their future studies and careers. Since all their core courses were taught in Chinese, they felt that it would be advantageous for them to have exposure to the English language in the non-Chinese general education courses. One student pointed out that some of the core courses, even though they were part of the Chinese programme, deal with theories originating from the west and so should be instructed in English to preserve the essence of such knowledge. He put the need to use EMI rather succinctly: "If I don't need to use English even in non-Chinese courses, I will have no chance to use English at all. If I am not able to understand or discuss anything in English after four years of study, I would feel that I have learnt nothing."

In addition to the importance of the English language for their future studies and employment, another reason for choosing English as the MOI was the current status of English as the de facto lingua franca for cross-border communication and academic research. They therefore were aware of the need to keep up or improve their English for their future development, and it was a generally held belief among the students that an EMI environment could force them to use English and as a result improve their English. The function as the lingua franca aside, English was the preferred language because of its association with high prestige and elitism in the local context. As mentioned above, one student pointed out that as EMI was a major trend and common practice among local universities, self-financing intuitions should also follow suit.

Despite the conviction of the need to uphold the EMI policy, the students did not seem to observe their own role in its implementation with the same resolve as discussed above. Moreover, most students tended to agree that there should be some flexibility under the EMI policy. None of the interviewees had strong objection to the use of some Cantonese in the classroom when necessary. Some students suggested that English should be the dominant language, while some Chinese, and in this context Cantonese, should be allowed for teachers to facilitate students' learning or cater for students' needs. In this sense, students in fact preferred English-led mixed-code instruction rather than an English only approach. It is worth noting that students were well aware of the distinct roles English and Chinese played: English was the language of academia while Chinese was their everyday language.

These students also voiced some concerns over using English as the medium of instruction. Their concerns included the possibility of the loss of ethnic identity of local students, the potential problems caused to students who attended CMI schools, their own lack of proficiency causing difficulties and lowered self-esteem, and the discouragement of their participation in class. A few students were also worried about the teachers' ability to deliver in English. Quoting from one student, 'If the teacher's English is poor, I'd rather he or she use Cantonese and not push it.' These students' views reflected some genuine concerns and obstacles in the implementation of the EMI policy as discussed in the literature. As for the use of Putonghua as the MOI, the majority of the interviewees decided that it would not be a plausible idea. The four main reasons that the students pointed out included:

- $\quad$ Their own low Putonghua proficiency;

- The teachers' general lack of mastery of Putonghua;

- The native tongue of the vast majority of the population being Cantonese rather than Putonghua;

- $\quad$ The EMI policy being applicable to speakers of all languages, including Putonghua speakers.

One student however supported the use of Putonghua as the MOI starting from primary school, in the belief that adopting a language as the MOI would facilitate students' acquisition of that language. Since Putonghua is gaining importance in Hong Kong with its ever closer ties with mainland China, proficiency in Putonghua would be an advantage. This view was however not shared by most others; on the contrary, the fear of Hong Kong people gradually losing their identity as a result of the adoption of Putonghua as the medium of instruction was brought up by a few students. This provided some evidence for the claim about the emergence of a local identify as a form of resistance to the dominance of Putonghua and mainland ideology (Chen, 2018; Choi, 2017).

Therefore, despite the drawbacks of learning in English, many more students still favoured English to Chinese than otherwise.

\subsection{The Coping Strategies}

As the majority of the students interviewed were supporters of the EMI policy, regardless of their ability to learn in English, they tended to downplay the difficulties they had and conceive the policy in their own way. As shown above, these students' understanding of the policy was hardly a "pure" one. They sometimes equated the use of mixed codes to the use of English, and they tended to be lenient about the adoption of other languages in the teaching and learning process. One student expressed explicitly this preference for a liberal approach to the 
implementation of the EMI policy, "The lecturers should use English throughout and as far as possible, but when we are stuck, they should stop and explain in Cantonese."

The modified interpretation and the flexible adaptation of EMI approach may be one of the strategies for students who are weaker in English to hold on to the much desired EMI policy. In addition to this, they coped with the policy with other strategies, which they may or may not have been aware of. The strategies that students resorted to included:

- $\quad$ Grouping with or seeking help from fellow students who were more competent at the language;

- Using online translation functions and online dictionaries;

- $\quad$ Searching for other people's work and adapting the materials for their own use;

- Asking others who are better at English to help proofread their work before submission;

- $\quad$ Using the internet to help them find references, check their grammar, look for synonyms, and so on;

- $\quad$ Reading more academic articles, books or newspapers in order to improve their English;

- Learning from the teacher's feedback on their language use, even though there was not a great deal of feedback reported.

Those who studied in CMI secondary schools naturally experienced more difficulty in adjusting to the EMI environment, as documented in literature (Evans \& Morrison, 2017). Most of them wished they had chosen or been able to choose to attend EMI secondary schools or courses. Some students expressed their regret, saying that they had "missed out a big time". The most common reason they cited was that since English was the main medium of instruction at college, it was difficult to relate all that they had learnt in Chinese, particular the Chinese terms, to the same content in English. This abrupt change from Chinese to English made it difficult for them to catch up. However, the difficulty to adapt to the EMI environment appeared to be short-lived. Those who were in their second year of study or above said that they had more or less overcome the difficulty, echoing what was discussed in the literature (Evans \& Morrison, 2016).

While it is obvious that most of these students needed help with their English as shown, most of them did not seem to find the EMI policy a challenge to them. One observation that could help explain this was that they did not set high standards and would settle for low accuracy of their own work. When asked to self-evaluate the overall quality of their own writing, most students described their writing as "average" or "satisfactory". One interviewee reported that he would always use simple sentence structures, such as the "subject-verb-object" structure, to make sure his language could be easily understood. In most of the interviews, there were students pointing out that they were not particularly concerned about their English grammar when they wrote their assignments. Their view was that as long as their work was comprehensible to the tutors, grammatical errors were no issue.

This may explain why these students, despite their average to low proficiency in the English language, still tended to show great support for the EMI policy for the advantages it may bring, without feeling overwhelming difficulties.

\subsection{The Appropriate MOI Policy from the Students' Perspective}

It is obvious that these students, regardless of their English standards, were advocates of the EMI policy, particularly the social science and science students. In addition to the lax approach to the implementation of the policy and the students' coping strategies discussed above, all the groups added the caveat that some courses, especially the general education courses, should be taught bilingually if they are about the local community or are steeped in Chinese culture, such as courses in Chinese medicine and about the Chinese society. The majority opinion was that the choice of MOI should be based on the nature of the subject, and therefore the instructors should be given the freedom to choose what language, or languages to use in their teaching.

While the majority of these students opined that the EMI policy should be maintained, some alternate views were proposed. One such view was that since a society thrives on diversity, there should be room for all the three languages in the classroom. Another view is that while English should be the main MOI, course instructors should be trusted with the decision of how the other languages should be used depending on the course nature, subject matter and the preference of the majority of the students. The third view, held by students from almost every group, was the need for the MOI to be consistent. These students believed that they could cope with instruction in any of the languages as long as they started using one of them as the MOI from an early age. However, no students suggested making Cantonese the MOI, with those from the science and social science programmes being most skeptical about the idea. The students were all aware of the role of English as a lingua 
franca, and unless Putonghua or less likely Cantonese achieve that kind of global recognition, English should unquestionably remain the MOI at tertiary education.

\section{Discussion}

\subsection{English-medium Teaching as an Irresistible Global Trend}

The medium of instruction policy of a country has always been subject to socio-political factors, and this is clearly illustrated in the case of Hong Kong. With the end of the colonial error and the growth in global influence of China, Putonghua has been actively promoted by the government and is competing with English in its influence in various sectors of the society. Coupled with the declining English standards of tertiary students in Hong Kong, some may speculate that the medium of instruction policy at tertiary level would evolve with the changing linguistic profile of the society and become bilingual or multilingual.

However, these internal forces for change may be counteracted by the global trend of internationalization of tertiary education. The spread of the English language has not slowed down with the end of the colonial regimes; its dominance nowadays owes as much (if not more) to the intensified forces of globalization in the 21 st Century (Jenkins, 2003). English has become an indispensable linguistic resource for socio-economic development, and Hong Kong, like other Southeast Asian societies, has the need to globalize and equip the younger generations with the linguistic capital they need to survive and thrive in the increasingly globalized economy (Lin \& Man, 2009). As a result, there is a rapidly growing demand for English-medium teaching in higher education as reflected by the increase in the number of EMI programmes in different regions of the world, particularly Southeast Asia (Kedzierski, 2016). The students themselves, as shown in this study, are aware of the pragmatic value of the English language. This means that in the current state of affairs, it would be going against the tide to promote any other language as the medium of instruction in higher education, not even at the self-financing institutions with limited-English-proficiency students. Even if a national language is imposed as the MOI, the policy may be reversed as a result of the global trend and pressure from the public as in the case of Malaysia (Lin \& Man, 2009).

\subsection{Concerns Around the Adoption of EMI}

One concern about the adoption of EMI is the difficulty in ensuring effectiveness in content-based learning using English while reaping its potential benefits for English learning, particularly among learners who do not necessarily possess the language proficiency required (Ferguson, 2006). Student participants of this study also expressed similar concerns. However, it is difficult to tell how EMI actually affects content learning, as there has been thus far a paucity of research on the impact of content learning in L2, and the findings have been inconclusive (Macaro, Curle, Pun, An, \& Dearden, 2018). Among this group of students, while there was some struggle in the transition from Chinese stream at secondary level to English-medium teaching at tertiary level, the difficulties did not seem to be insurmountable. This result lines up with findings from another study (Evans \& Morrison, 2016). There seems to be no reason why students should not continue to be educated in English, a language of their desire and of the highest currency.

However, two issues concerning the effects of EMI on English learning were identified in this study. The first issue is that the effects EMI may have on students' English learning may not necessarily be positive if students are not in a position to benefit from such a language policy. While the students in this study were convinced that they were actually learning in English, they were in fact adapting to the EMI environment in ways that may lead to the deceptive view that their English was adequate for academic purposes, and their strategies to cope with the language demand may foster undesirable attitudes and habits in using and learning English. While their counterparts in the government-funded universities may be making progress in meeting the requirements of an EMI environment (Evans \& Morris, 2011), these students are mostly a long way from being able to achieve such a goal. They need to come to this realization and make more of an effort to use this global language appropriately, and this may require a stronger assertion of the EMI policy at the institutional level.

Apart from the potential adverse effects on English learning discussed above, another issue is that students may not be aware that their strong belief in EMI may not be firmly grounded. They generally view EMI as a way to learn English, and their support for the EMI policy largely stems from their belief that by learning in English, their English proficiency will improve. Although studies have been conducted in various contexts to explore the impact of EMI on language learning (e.g. Hui, Li, \& Lei, 2014; Lin \& Morris, 2010; Rogier, 2012), the focuses, designs and findings of these studies are not comparable and thus may not provide sufficient evidence that EMI can efficiently improve students' English competence (Ernesto et al., 2017). If this belief about the desirable effects on English learning is a myth (Lin \& Man, 2009), it is hard to determine whether the adherence to the EMI policy, particularly among students who may not be adequately equipped for it, is worth the effort. 
In light of these issues and the doubt of the benefits of EMI, the advocation of using English only in instruction among these students may deserve more serious consideration. If the policy is to be upheld, more effort needs to be exerted at the institutional level to help students meet the challenge, rather than hoping medium-instruction can automatically improve students' English. It may not be adequate just to require students to take some English courses early in their programmes of study without providing any further systematic support for them afterwards. Even though these students are at tertiary level study, they may still benefit from some kind of English enhancement programme offered by the institution (Yeung \& Li, 2018). If students are not given the help they need, it may perhaps make better sense to consider giving the majority of students' L1, Cantonese, an official role in the tertiary classroom with students of limited English proficiency. Rather than officially holding on to the EMI policy without consistent commitment to it causing confusion and perhaps also undesirable effects, bilingual pedagogical approaches may seem to be the way out. More practical approaches to solving the problems arising from students' lack of English proficiency may include the adoption of a bilingual education policy or the promotion of the use of translanguaging strategies in the instructional process (e.g. Garcia, 2011).

\section{Conclusion and Recommendations}

Exploring the MOI issue from the students' perspective, this study provides some insight in the actual implementation of the EMI policy in higher education in Hong Kong. The findings above address the research questions by suggesting that the EMI policy, though rather opaque and often practised in an arbitrary manner at the self-financing tertiary institutions in Hong Kong, is still preferred by the majority of the students regardless of their English proficiency. Despite the sociolinguistic changes and the government's effort to elevate the status of Putonghua, the beliefs that English proficiency is a valuable asset and that English is a prestigious language still remain strong.

If students' preferences are given due consideration, the issue is not whether the EMI policy should be upheld; rather, it is how it could be achieved and what support should be provided for the students. No doubt the students themselves have found their way around the difficulties they encounter in the instructional process, but whether their strategies and approaches are effective or helpful to them in the long run deserves attention. The low English standards that students set for themselves, for example, are alarming and may affect the competitiveness of not only themselves but also the society as a whole. If English-medium teaching is an irresistible trend in higher education, perhaps more effort could be made at the institutional level to help students adopt to it. In addition to creating an environment that encourages the use of English, English learning should be more seriously considered to be part of tertiary education, rather than a cosmetic component that students are somehow required to complete before taking on the more serious aspect of content learning.

Although the findings presented above only reflect the students' views, they may point to some directions in which the MOI issue could be further explored and addressed. While paying heed to students' preferences, policy-makers may also need to balance the benefits and drawbacks of adhering to the EMI policy. Whether to insist on English-medium teaching with enhanced English support for the students or to address the problems by introducing alternative language policies may be a dilemma to be faced by policy-makers in the near future.

\section{Acknowledgements}

This paper reports findings from the project titled "An exploratory study on the medium of instruction (MOI) of the self-financing tertiary institutions in Hong Kong" funded by the Research Grants Council of Hong Kong under the Faculty Development Scheme (Project Ref. No.: UGC/FDS17/H01/15).

\section{References}

Anderson, G. (1990). Fundamentals of educational research. London: The Falmer Press. https://doi.org/10.3102/0013189X019003039

Bacon-Shone, J., \& Bolton, K. (2008). Bilingualism and multilingualism in the HKSAR: Language surveys and Hong Kong's changing linguistic profile. In K. Bolton, \& H. Yang (Eds.), Language and society in Hong Kong. Hong Kong: Open University of Hong Kong.

Brimer, A., Cheng, W., Ip, B., Johnson, K., Lam, R., Lee, P., Leung, J., Sweeting, A., \& Tong, S. M. (1985). The effects of the medium of instruction on the achievement of Form 2 students in Hong Kong secondary schools. Hong Kong: Hong Kong Government, Education Department, Education Research Establishment and University of Hong Kong, Faculty of Education.

Chaudron, C. (1988). Second language classrooms: Research on teaching and learning. Cambridge: Cambridge University Press. https://doi.org/10.1017/CBO9781139524469 
Casey, M. A., \& Kueger, R. A. (2000). Focus groups: A practical guide for applied research (3rd ed.). Thousand Oaks, CA: Sage.

Chen, K. H. Y. (2018). Ideologies of language standardization: The case of Cantonese in Hong Kong. In J. W. Tollefson, \& M. Pérez-Milans (Eds.), The Oxford handbook of language policy and planning. Oxford Handbooks Online.

Choi, P. K. (2017). Should the Chinese language be taught in Putonghua? Contested identities in Post-1997 Hong Kong. Asia Colloquia Papers 7(1). Toronto: York Centre for Asian Research. Retrieved from www.yorku.ca/ycar

Corson, D. (2009). Language policy in schools. New York: Routledge.

Dawson, S. et al. (1993). A manual for the use of focus groups. International Nutrition for Developing Countries (INDFC).

Denscombe, M. (2007). The good research guide for small-scale social research projects (3rd ed.). New York: McGraw-Hill.

Education Bureau. (2010). Enriching our language environment, realising our vision: Finetuning of medium of instruction for secondary schools. Hong Kong Special Administrative Region, China.

Evans, S. (2010). Language in transitional Hong Kong: Perspectives from the public and private sectors. Journal of Multilingual and Multicultural Development, 31(4), 347-363. https://doi.org/10.1080/01434632.2010.497218

Evans, S., \& Morrison, B. (2011). The student experience of English-medium higher education in Hong Kong. Language and Education, 25(2), 147-162. https://doi.org/10.1080/09500782.2011.553287

Evans, S., \& Morrison, B. (2016). Adjusting to higher education in Hong Kong: the influence of school medium of instruction. International Journal of Bilingual Education and Bilingualism, 1-14. https://doi.org/10.1080/13670050.2016.1228600

Evans, S., \& Morrison, B. (2017). English-medium instruction in Hong Kong: illuminating a grey area in school policies and classroom practices. Current Issues in Language Planning, 18(3), 303-322. https://doi.org/10.1080/14664208.2016.1270106

Ferguson, G. (2006). Language planning and education. Edinburgh, Scotland: Edinburgh University Press

Flowerdew, J., Li, D., \& Miller, L. (1998). Attitudes towards English and Cantonese among Hong Kong Chinese university lecturers. TESOL Quarterly, 32, 201-231. https://doi.org/10.2307/3587582

García, O. (2011). Bilingual education in the 21st century: A global perspective. John Wiley \& Sons.

Helot, C., \& Laoire, M. O. (Eds.). (2011). Language policy for the multilingual classroom: Pedagogy of the possible. Bristol, Buffalo, Toronto: Multilingual Matters.

HKSAR Government. (2013). Enrolments of Full-time Accredited Self-financing Post-secondary Programmes, 2001/02 to 2012/13. Hong Kong: Information Portal for Accredited Post-secondary Programmes. Retrieved from http://www.ipass.gov.hk/edb/index.php/en/home/statheader/stat/stat_el_index

Howlett, B. (1997). Hong Kong - A new era. Hong Kong: Government Printer.

Hu, G., Li, L., \& Lei, J. (2014). English-medium instruction at a Chinese University: Rhetoric and reality. Language Policy, 13(1), 21-40. https://doi.org/10.1007/s10993-013-9298-3

Jenkins, J. (2003). World Englishes: A resource book for students. Psychology Press.

Kan, W. H. V., Lai, K. C., Kirkpatrick, T. A., \& Law, A. (2011). Fine-tuning Hong Kong's medium of instruction policy. Hong Kong, China: The Hong Kong Institute of Education.

Kedzierski, M. (2016). English as a medium of instruction in East Asia's higher education sector: a critical realist Cultural Political Economy analysis of underlying logics. Comparative Education, 52(3), 375-391. https://doi.org/10.1080/03050068.2016.1185269

Kirkpatrick, T. A. (2011). Internationalization or Englishization: Medium of instruction in today's universities.

Li, D. C. S. (1999). The functions and status of English in Hong Kong: A post-1997 update. English World-Wide, 20(1), 67-110. https://doi.org/10.1075/eww.20.1.03li

Li, D. C. S. (2009). Towards 'biliteracy and trilingualism' in Hong Kong (SAR): Problems, dilemmas and stakeholders' views. AILA Review, 22, 72-84. https://doi.org/10.1075/aila.22.06li 
Li, D. C. S. (2013). Linguistic hegemony or linguistic capital? Internationalization and English-medium instruction at the Chinese University of Hong Kong (CUHK). In A. Doiz, D. Lasagabaster, \& J. M. Sierra (Eds.), English-medium instruction at universities. Global challenges (pp. 65-83). Bristol, Buffalo, Toronto: Multilingual Matters.

Li, N., Leung, D. Y. P., \& Kember, D. (2001). Medium of instruction in Hong Kong universities: the mis-match between espoused theory and theory in use. Higher Education Policy, 13, 293-312. https://doi.org/10.1016/S0952-8733(01)00021-6

Lin, A. M. (2015). Conceptualising the potential role of L1 in CLIL. Language, Culture and Curriculum, 28(1), 74-89. https://doi.org/10.1080/07908318.2014.1000926

Lin, A. M. Y., \& Man, E. Y. F. (2009). Bilingual education: Southeast Asian perspectives. Hong Kong: Hong Kong University Press. https://doi.org/10.5790/hongkong/9789622099586.001.0001

Lin, L. H. F., \& Morrison, B. (2010). The impact of the medium of instruction in Hong Kong secondary schools on tertiary students' vocabulary. Journal of English for Academic Purposes, 9(4), 255-266. https://doi.org/10.1016/j.jeap.2010.09.002

Lo, Y. Y., \& Lo, S. C. E. (2014). A meta-analysis of the effectiveness of CMI and EMI education in Hong Kong. Review of Educational Research, 84(1), 47-73. https://doi.org/10.3102/0034654313499615

Macaro, E., Curle, S., Pun, J., An, J., \& Dearden, J. (2018). A systematic review of English medium instruction in higher education. Language Teaching, 51(1), 36-76. https://doi.org/10.1017/S0261444817000350

Morgan, D. L. \& Krueger, R. A. (1993). When to use focus groups and why. In D. L. Morgan (Ed.). Successful focus groups: Advancing the state of the art. Newbury Park: Sage. https://doi.org/10.4135/9781483349008.n1

Patton, M.Q. (2002). Qualitative evaluation and research methods (3rd ed.). Thousand Oaks, CA: Sage.

Phillipson, R. (2006). Figuring out the Englishisation of Europe. In C. Leung, \& J. Jenkins (Eds.), Reconfiguring Europe (pp. 65-86). London: Equinox.

Poon, A. Y. K. (2004). Language Policy of Hong Kong: Its impact on language education and language use in post-handover Hong Kong. Journal of Taiwan Normal University: Humanities and Social Sciences, 49(1), 53-74.

Ricento, T. (2006). An introduction to language policy: Theory and method. Malden, MA: Blackwell. https://doi.org/10.1007/s10993-005-3200-x

Rogier, D. (2012). The effects of English-medium instruction on language proficiency of students enrolled in higher education in the UAE. Retrieved from https://ore.exeter.ac.uk/repository/bitstream/handle/10036/4482/RogierD.pdf?sequence=2

Stewart, D. W., \& Shamdasani, P. N. (1990). Focus groups: Theory and practices. Newbury Park: Sage.

The Chinese University of Hong Kong. (2007). Report of the Committee on Bilingualism. Retrieved from https://www.cuhk.edu.hk/policy/english/bilingualism/bilingualism.html

The Constituent Theme Funding of "Language in Education and Assessment". (2006). HKU-wide Sociolinguistic Survey. Retrieved from The Constituent Theme Funding of "Language in Education and Assessment" website http://www.fe.hku.hk/clear/index.html

Tsui, B. M. A. (2004). Medium of instruction in Hong Kong: One country, two systems, whose language? In J. W. Tollefson, \& B. M. A. Tsui (Eds.), Medium of instruction policies: Which agenda? Whose agenda? (pp. 97-110). Mahwah, New Jersey: Lawrence Erlbaum Associates.

Walters, S., \& Balla, J. (1998). Medium of instruction: Policy and reality at one Hong Kong tertiary institution. In M. C. Pennington (Ed.), Language in Hong Kong at century's end (pp. 365-389). Hong Kong: Hong Kong University Press. https://doi.org/10.1023/A:1003035929216

Wisker, G. (2001). The postgraduate research handbook. U.K.: Palgrave.

Yeung, M., \& Li, T. (2018). Student preferences and expectations: Some practical tips for designers of English enhancement programmes. English Language Teaching, 11(2), 172. https://doi.org/10.5539/elt.v11n2p172

Vygotsky, L. S., Rieber, R. W., \& Carton, A. S. (1987). The collected works of L. S. Vygotsky. New York: Plenum Press. 


\section{Copyrights}

Copyright for this article is retained by the author(s), with first publication rights granted to the journal.

This is an open-access article distributed under the terms and conditions of the Creative Commons Attribution license (http://creativecommons.org/licenses/by/4.0/). 